\title{
EDITORIAL
}

\section{MERS-CoV: Current Global Status and Threats for Bangladesh}

While writing this editorial the first case of "Middle East Respiratory Syndrome corona virus”(MERS-CoV) is already detected in Bangladesh in a person returning from middle east. MERS-CoV is a novel corona virus first reported on $24^{\text {th }}$ September,2012 on proMed -mail by Egyptian virologist Dr. Ali Mohammad Jaki in Jeddah.He isolated and identified a new corona virus from a 60 year old male patientwith acute pneumonia and renal failure ${ }^{1}$. Until $23^{\text {rd }}$ may2013, MERS-CoV had frequently been referred to as a SARS like virus. ${ }^{2}$

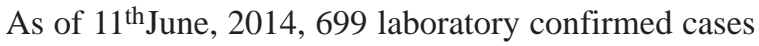
of human infections with MERS-CoV have been reported to WHO, including at least 209 deaths. Overall $63.5 \%$ of cases reported $(n=695)$ are male and the median age is 47 years old. To date , the affected countries in the Middle East include Iran, Jordan, Kuwait, Lebanon, Oman, Qatar, Saudi Arabia(KSA), United Arab Amirates (UAE) and Yemen; in Africa: Algeria Egypt And Tunesia; In Europe: France,Germany,Greece, Italy, The Netherland and the United Kingdom; in Asia; Malaysia,philippines and Bangladesh and in North America: the united states of America. ${ }^{3}$

Bangladesh reported its first laboratory confirmed case on 15th June,2014 in a 50 year old patient who had travelled Abudhabi recently. All cases in newly affected countries have a history of residence in or traveled to the Middle East or contacts with travellers returning from these areas.The infection has occurred in the community (sporadic cases with unknown exposure), in families (contact with infected family members) and in health care facilities (patients and health care worker from whence the majority cases are reported)

The incubation period of MERS-CoV is estimated to be up to two weeks, but likely shorter in most cases, however more data are required to refine the estimate. There is increasing trend of severe cases of MERS-CoV infections in older patients with comorbidity and milder cases in their contacts .Most of the cases recently reported from KSA reflect infection acquired through human to human transmission in health care settings and there is no evidence of sustained human to human transmission in the community. ${ }^{3}$

Most confirmed cases have presented with or later developed severe lower respiratory tract infection. The most frequently reported symptoms were fever, cough and breathlessness and complicated by ARDS, renal insufficiency and shock. ${ }^{4}$ Of the First 47 cases in Saudi Arabia 89\% required management in intensive care and $72 \%$ required mechanical ventilation. If anyone develops lower respiratory infections within 14 days after returning from Middle East, must seek medical attention.Laboratory confirmation of MERS-CoV infections to date largely been by real- time reverse transcription polymeras4e chain reaction(RT-PCR). ${ }^{5}$

There is no current treatment or vaccination available for MERS-CoV Interferon alfa 3b and ribavirin may work primarily by reducing inflammation of lungs and promoting healing by altering the host response rather than directly targeting the virus.

Preventive measures are extremely important which includes use of personal protective equipment( mask, gown, gloves by Health care worker and exposed people), hand hygiene, influenza vaccination, patient isolation in a single bed negative pressure room.

Hajj and Umrah draws some of the largest crowds in the world, and the large crowds bring some health and safety risk. The virus can spread from person to person when people are touching or very near each other, thus pilgrims in crowd may be at risk. About ten thousands Muslims of Bangladesh travel to Saudi Arabia each yearto perform Hajj. So we should pay attention to our health when travelling in the Arabian Peninsula.

\section{Actions to take before Umra or Hajj or travel to} Middle East

- pilgrims with pre-existing major medical conditions (e.g. chronic diseases such as diabetes, chronic lung disease, immunodeficiency) are 
advised about the increased risk of MERS-CoV infection and high risk person are prohibited.

- $\quad$ Pilgrims are to be educated about on general travel health precautions.

- $\quad$ Medical staff accompanying pilgrims should be up to date on MERS-CoV information and guidance

Actions to take during Umra or Hajj or travel to Middle East

- Travellers who develop a significant acute respiratory illness with fever and cough (severe enough to interfere with usual daily activities) should be advised to:

- Minimize their contact with others to keep from infecting them;

- Cover their mouth and nose with a tissue when coughing or sneezing and discard the tissue in the trash after use and wash hands afterwards, or, if this is not possible, to cough or sneeze into upper sleeves of their clothing, but not their hands. And report to the medical staff accompanying the group or to the local health services.

Actions to take after Umra or Hajjor travel to Middle East

- $\quad$ Returning pilgrims should be advised that if they develop a significant acute respiratory illness with fever and cough during the two weeks after their return, they should seek medical attention and immediately notify their local health authority.

- $\quad$ Persons who have had close contact with a pilgrim or traveller with a significant acute respiratory illness with fever and cough and who themselves develop such an illness should be advised to report to local health authorities to be monitored for MERS-CoV.

- Practitioners and facilities should be alerted to the possibility of MERS-CoV infection in returning pilgrims with acute respiratory illnes
Enhancing infection prevention and control awareness and implementation measures is critical to prevent possible spread of MERS- CoVinfections in health care facilities. Health care facilities that provide care for patients suspected or confirmed to be infected with MERS-CoV infections should take appropriate measures to decrease the risk of transmission to other patients , health care worker and visitors. Bangladesh should maintain high level of vigilance as we have large number traveller or workers returning from the Middle East.

(J Banagladesh Coll Phys Surg 2014; 32: 122-123)

\section{Prof. HAM Nazmul Ahasan}

Professor and Head, Dept. of Medicine

Dhaka Medical College

\&

Editor-in-Chief, Journal of Bangladesh College of Physicians \& Surgeons.

\section{Reference:}

1. Zaki AM, van Boheemeens S, Bestebroer TM, Osterhaus AD, Fouchier RA. Isolation of a novel corona virus from a man with pneumonia I n Saudi Arabia. N Engl J Med 2012; 3667: 1814-1820

2. World health Organisation. Middle East respiratory syndrome corona virus” ( MERS-CoV) - updates 23 september2012 to 28 august 2013.

3. World health Organisation. Middle East respiratory syndrome corona virus” ( MERS-CoV) -summary and literature updateas of 11 June 2014

4. Yaseen M, Ahmed A, HananHB, Hani N, Abdulaziz SA, Alaa G, Hassan H. Clinical course and outcome of critically ill patients with Middle East respiratory syndrome corona virus infection. Ann intern Med 2014; 160: 389-397

5. Assiri a, Al-TawfiqjA, Al-Rabeeah AA, Al Rabiah FA, AlBarrak et al. Epidemological, demographic and clinical characteristics of 47 cases of Middle East respiratory syndrome corona virus disease from Saudi Arabia: a escriptive study. Lancet infect Dis 2013 